\title{
Amniotic-Fluid Ingestion Enhances the Central Analgesic Effect of Morphine
}

\author{
J. M. DI PIRRO, A. C. THOMPSON AND M. B. KRISTAL ${ }^{1}$ \\ Department of Psychology, State University of New York at Buffalo, Buffalo, NY 14260
}

Received 26 November 1990

\begin{abstract}
DI PIRRO, J. M., A. C. THOMPSON AND M. B. KRISTAL. Amniotic-fluid ingestion enhances the central analgesic effect of morphine. BRAIN RES BULL 26(6) 851-855, 1991.-Amniotic fluid and placenta contain a substance (POEF) that when ingested enhances opioid-mediated analgesia produced by several agents (morphine injection, vaginal/cervical stimulation, late pregnancy, footshock), but not that produced by aspirin injection. The present series of experiments employed quaternary naltrexone, an opioid antagonist that does not readily cross the blood-brain barrier, in conjunction with either peripheral or central administration of morphine, to determine whether amniotic-fluid ingestion (and therefore POEF ingestion) enhances opioid-mediated analgesia by affecting the central and/or peripheral actions of morphine. The resuits suggest that POEF affects only the central analgesic effects of morphine.
\end{abstract}

POEF Analgesia Pain Rats Morphine Opioids Placenta Quaternary naltrexone Amniotic fluid Placentophagia Naltrexone methobromide

INGESTION of a substance contained in amniotic fluid and placenta, POEF (Placental Opioid-Enhancing Factor), enhances analgesia produced by late pregnancy, peripheral morphine injection, footshock, and vaginal/cervical stimulation in rats. However, amniotic fluid ingestion, or placenta ingestion, not paired with administration of an analgesic or an analgesia-producing procedure, does not produce analgesia (3-8). Furthermore, this enhancement appears to be specific to opioid-mediated analgesia: treatment with opioid antagonists such as naltrexone and naloxone blocks the enhancement $(6,7)$, and POEF ingestion does not enhance nonopioid-mediated analgesia produced by aspirin injection in naltrexone-treated rats (5).

The present studies represent a step toward elucidating the mechanism by which POEF enhances opioid-mediated analgesia by investigating whether POEF enhances the central or peripheral action of opioids. In order to localize the action of POEF, we used a quaternary derivative of the opiate antagonist naltrexone, naltrexone methobromide $(\mathrm{QN})$. QN penetrates the bloodbrain barrier less readily than its tertiary counterpart and can thus be used to discriminate peripheral from central opioid action $(2,12)$. Morphine has both peripheral and central actions, although the more important locus, for analgesia, is central $(9,13)$. Our attempt to determine whether POEF acts centrally, peripherally, or both centrally and peripherally, on morphine-mediated analgesia rested on three premises. (a) Enhancement of systemic-morphine-mediated analgesia by ingested POEF during a blockade of peripheral opiate receptors (by peripheral administration of QN), would indicate a central opioid mechanism. Similarly, (b) enhancement by ingested POEF of analgesia produced by centrally administered morphine during a blockade of peripheral opiate receptors (by peripheral administration of $\mathrm{QN}$ ), would also support the contention of at least a central action for POEF.
Finally, (c) failure of ingested POEF to enhance systemic-morphine-mediated analgesia during a blockade of central opiate receptor sites (by central administration of $\mathrm{QN}$ ) would provide strong evidence for only a central action of POEF.

\section{EXPERIMENT 1}

The first experiment was designed to examine whether restricting morphine to its central action still permitted analgesia enhancement by ingestion of POEF in amniotic fluid. Enhancement of systemically administered morphine was assessed while peripheral opioid receptors were blocked by systemically administered QN.

METHOD

\section{Subjects}

The subjects were 32 nulliparous, female, Long-Evans (hooded) rats, $75-105$ days of age, weighing $256 \pm 3.6 \mathrm{~g}$. The rats were housed individually in $24.5 \times 18 \times 18-\mathrm{cm}$ suspended wiremesh cages in a colony maintained on a $14-\mathrm{h}$ on/10-h off lightdark cycle (lights on at $0500 \mathrm{~h}, \mathrm{EST}$ ). All subjects had unlimited access to food (Agway Prolab Rat/Mouse/Hamster Formula 3000) and water, except for a three-hour period prior to, and during, testing.

\section{Apparatus}

Analgesia (increase in pain threshold) was measured using a radiant-heat tail-flick algesiometer described previously $(4,8)$. Pain threshold was represented as the mean of the last 3 of 4 tail-flick latency (TFL) trials, recorded at 30-s intervals. Trials

${ }^{1}$ Requests for reprints should be addressed to Dr. Mark B. Kristal, Department of Psychology, SUNY at Buffalo, Buffalo, NY 14260. 
were terminated at $8 \mathrm{~s}$ to avoid tissue damage. During testing, rats were restrained in $5 \times 21-\mathrm{cm}$ opaque, polyvinyl tubes to which they had been habituated for $1 \mathrm{~h} /$ day for 5 days prior to testing.

Orogastric infusions of amniotic fluid (AF) and control fluid were performed through PE 160 tubing, attached to a blunted 18-ga needle fitted to a $0.25-\mathrm{ml}$, glass, tuberculin syringe. Each rat was habituated to the intubation procedure (with a blank infusion) once each day for 5 days prior to testing.

\section{Procedure}

The overall design of the experiment was a $2 \times 2 \times 2$ factorial: Antagonist [QN ( $8 \mathrm{mg} / \mathrm{kg}, \mathrm{SC})$; saline vehicle, Veh] $\times$ Agonist [morphine sulfate, MS (3 mg/kg, IP); saline, Sal] $\times$ Enhancer [amniotic fluid, AF (0.25 ml, PO); control fluid, BB]. The dose of QN chosen was based on reported differences in potency between naltrexone and QN, and on the reported threshold for selective peripheral action $(1,11,12)$. Rats were tested at both levels of the Agonist factor in a balanced design. Tests were separated by a 1-week interval.

At the start of the test, each rat was injected with the antagonist or vehicle. Twenty minutes later, a baseline TFL was determined for each rat, followed immediately by an injection of agonist or vehicle. The dose of morphine sulfate was chosen because it usually produces a small (about 15\% increase from baseline TFL) but reliable amount of analgesia; this level of analgesia enables us to detect enhancement without the production of too many responses at the 8-s ceiling. Enhancer or control fluid was infused $15 \mathrm{~min}$ after the injection of agonist. Fifteen minutes after infusion, a second TFL was determined. The mean percent change from baseline TFL was calculated for each rat, and served as the dependent variable for all the experiments reported here.

Amniotic fluid for orogastric intubation was collected from donor rats euthanized with $\mathrm{CO}_{2}$ on Day 21 of pregnancy, and stored in a manner previously described $(4,6)$. The control substance for AF, beef bouillon (BB), was prepared from Wyler's Instant Beef Bouillon diluted to half the strength indicated in the manufacturer's instructions, and stored and administered in a manner identical to that of the AF.

\section{RESULTS AND DISCUSSION}

The results of Experiment 1 are depicted in Fig. 1.

Baseline TFLs did not differ between Antagonist groups (QN: mean $=3.80 \pm 0.04 \mathrm{~s}$; Veh: mean $=3.67 \pm 0.05 \mathrm{~s}), \mathrm{F}(1,28)=$ $3.27, p>0.05$. Because the baseline TFLs were measured after the Antagonist treatment, this result indicates that treatment with QN did not affect pain threshold before the Agonist and Enhancer were administered.

The 3-way ANOVA (Antagonist $\times$ Agonist $\times$ Enhancer) revealed a significant main effect of Antagonist, $F(1,28)=6.07$, $p<0.025$; this was attributable to the fact that MS-treated rats injected with QN showed lower pain thresholds than did those injected with the antagonist vehicle.

There was also a significant Agonist $\times$ Enhancer interaction, $\mathrm{F}(1,28)=6.25, p<0.02$. The subsequent simple-effects probe of this interaction indicated that AF infusion enhanced the analgesia produced by morphine; $\mathrm{MS}+\mathrm{AF}$ treatment resulted in higher pain thresholds than did MS + BB treatment, $F(1,56)=$ 9.2, $p<0.01$, or than Sal $+\mathrm{AF}$ treatment, $\mathrm{F}(1,28)=40.39$, $p<0.001$

Although the results of the 3-way ANOVA indicate that en-

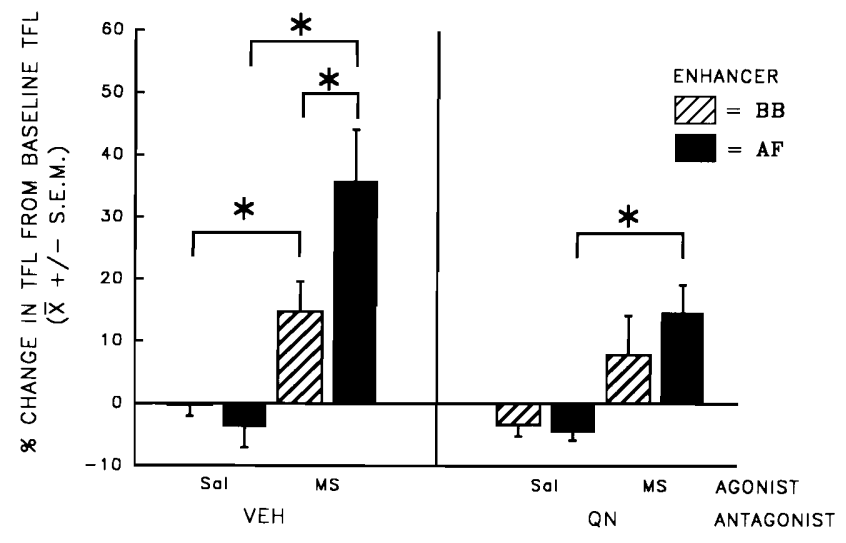

FIG. 1. Mean percent change ( \pm S.E.M.) from baseline tail-flick latency (TFL) of rats pretreated with systemic antagonist [quaternary naltrexone (QN) or vehicle (VEH)], then treated with systemic agonist [morphine (MS) or saline (Sal)] and an orogastric infusion of enhancer [amniotic fluid (AF) or beef bouillon control (BB)]. $\mathrm{n}=8$ /group; ${ }^{*} p<0.01$.

hancement of analgesia by AF does not require the involvement of peripheral opioid receptors, the analysis did not provide a direct test of the effect of $\mathrm{AF}$ on analgesia under the $\mathrm{QN}$ condition. Therefore, we used subsequent pairwise comparisons to test the effect of various combinations of Agonist and Enhancer among only $\mathrm{QN}$-injected rats (i.e., $\mathrm{AF}+\mathrm{MS}$ vs. $\mathrm{BB}+\mathrm{MS}$, $\mathrm{AF}+\mathrm{MS}$ vs. $\mathrm{AF}+\mathrm{Sal}$, and $\mathrm{BB}+\mathrm{MS}$ vs. $\mathrm{BB}+\mathrm{Sal})$. These comparisons confirmed that $\mathrm{AF}$ enhanced the analgesia produced by MS in QN-treated rats; the MS + AF Group showed analgesia whereas the MS + BB Group did not $[\mathrm{MS}+\mathrm{AF}$ vs. Sal + AF: $\mathrm{F}(1,7)=17.36, p<0.01 ; \mathrm{MS}+\mathrm{BB}$ vs. Sal + BB: $\mathrm{F}(1,7)=2.50, p>0.05]$.

These results indicate that although systemic QN attenuated morphine-induced analgesia, by elimination of the peripheral effects of morphine, AF ingestion still enhanced the remaining analgesia (that attributable to the central effects of morphine). Therefore, ingested POEF affects at least the central site of action of morphine on analgesia.

\section{EXPERIMENT 2}

In the second experiment, we tested whether amniotic fluid ingestion enhances analgesia induced by a central injection of morphine. Experiment $2 \mathrm{~A}$ examined this possibility when peripheral opioid receptors were active; Experiment $2 \mathrm{~B}$ examined the possibility with peripheral opioid receptors blocked by systemic administration of QN.

Experiment 2A: Central Morphine Administration and Active Peripheral Receptors

METHOD

\section{Subjects}

The subjects were 28 nulliparous, female, Long-Evans (hooded) rats, 90-150 days of age, weighing $290 \pm 5.1$ g. All rats were morphine-naive, but had participated in a study 4-6 weeks prior to this experiment in which they received a single TFL test. Initially, the rats were maintained identically to the rats in Experiment 1 . After surgery for implantation of indwelling intracerebroventricular (ICV) cannulae, they were housed individually 


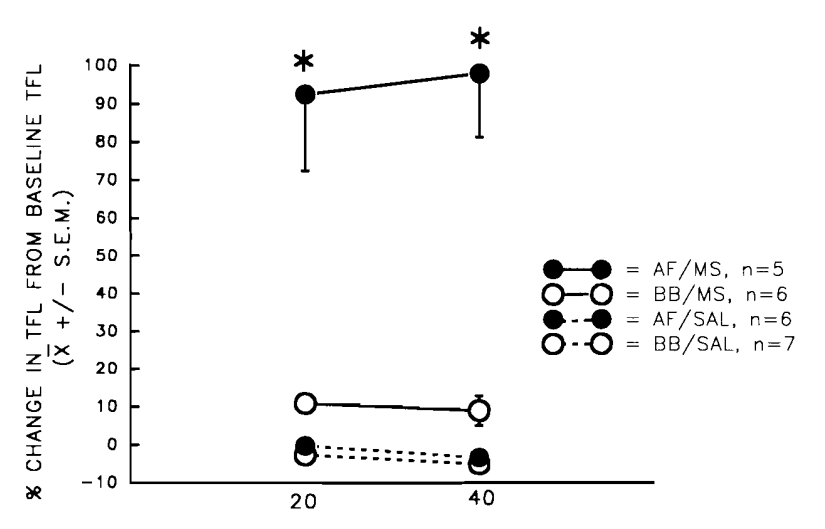

TIME IN MIN AFTER FLUID INFUSION

FIG. 2. Mean percent change ( \pm S.E.M.) from baseline tail-flick latency (TFL) of rats treated with central agonist [morphine (MS) or saline $(\mathrm{SAL})]$ and an orogastric infusion of enhancer [amniotic fluid (AF) or beef bouillon control (BB)]. ${ }^{*} p<0.0001$.

in $32 \times 20 \times 20-\mathrm{cm}$, free-standing, clear plastic cages. Food and water were available ad lib, except for a 3 -h period prior to, and during, testing.

\section{Apparatus}

Pain-threshold testing and orogastric intubation were performed the same as in Experiment 1.

Drug microinjections were performed using a Harvard microinfusion pump (Model 944).

\section{Procedure}

The overall design of the experiment was $2 \times 2 \times 2$ factorial: Agonist [morphine, MS (2.5 $\mu \mathrm{g}$ in $2 \mu \mathrm{l}$, ICV); saline, Sal] $\times$ Enhancer [AF, BB $(0.25 \mathrm{ml}, \mathrm{PO})] \times$ Time $(20$ and $40 \mathrm{~min}$ after orogastric infusion). Each rat was randomly assigned to one Agonist $\times$ Enhancer group and tested at both postinfusion time intervals.

Rats were anesthetized during surgery with $40 \mathrm{mg} / \mathrm{kg}$, IP, pentobarbital sodium $(65 \mathrm{mg} / \mathrm{ml})$ after premedication with $4 \mathrm{mg} /$ $\mathrm{kg}, \mathrm{SC}$, atropine sulfate $(5 \mathrm{mg} / \mathrm{ml})$ to suppress mucus secretion. Each rat was treated with an antibiotic (Combiotic, $0.5 \mathrm{cc}, \mathrm{IM}$ ) as a prophylactic measure. The intracerebroventricular implant consisted of a 22-ga stainless-steel guide cannula (Plastic Products) inserted into the right lateral ventricle according to the following coordinates: A-P $=-0.2 \mathrm{~mm}$ (bregma); $\mathrm{L}=-2.4 \mathrm{~mm}$ (center of midsagittal sinus); $\mathrm{D}-\mathrm{V}=-3.1 \mathrm{~mm}$ (cortex), with the incisor bar positioned $5 \mathrm{~mm}$ above the interaural line (10). The guide cannula was anchored to the skull with dental cement affixed to $0-80$ stainless steel screws. During microinjection, the internal cannula protruded $1 \mathrm{~mm}$ beyond the tip of the guide cannula. The drug was delivered intraventricularly at a rate of 1 $\mu \mathrm{l} / \mathrm{min}$.

The dose of morphine used $(2.5 \mu \mathrm{g})$ was chosen so as to produce a near-threshold response $(10-20 \%$ average increase in TFL in pilot rats). This level of elevation is behaviorally equivalent to the amount of analgesia produced by the dose of morphine administered during systemic injection $(3 \mathrm{mg} / \mathrm{kg})$ in Experiment 1.

Rats were allowed a 2-week recovery period before behav-

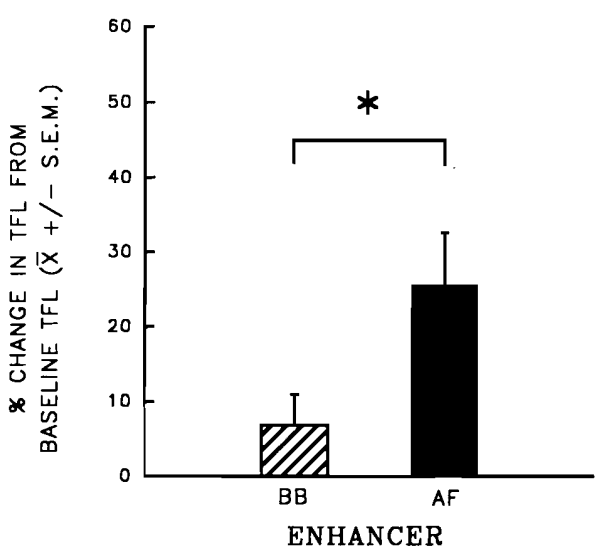

FIG. 3. Mean percent change ( \pm S.E.M.) from baseline tail-flick latency (TFL), at $20 \mathrm{~min}$ after orogastric infusion, of rats pretreated with systemic antagonist [quaternary naltrexone $(\mathrm{QN})]$, then treated with central agonist [morphine (MS)] and an orogastric infusion of enhancer [amniotic fluid (AF) or beef bouillon control (BB)]. $\mathrm{n}=7 /$ group; ${ }^{*} p<0.05$.

ioral testing began. They were habituated to the removal of cannula caps daily for at least 5 days prior to the first day of testing.

At the start of the test, baseline pain threshold was determined for each rat, followed immediately by an injection of morphine or vehicle into the right lateral ventricle. Ten minutes after the end of the injection, AF or BB was infused orogastrically. Pain threshold was again measured 20 and $40 \mathrm{~min}$ after the infusion. The dependent measures were calculated as percent change in pain threshold from pretreatment baseline at 20 and 40 min postinfusion.

At the conclusion of the study, each rat was overdosed with pentobarbital sodium, IP, and given a $1.0-\mu 1$ ICV injection of methyl blue dye to determine subsequently whether the cannula was located in the ventricle. The brains were perfused and removed, and the placement verified by histological examination of frozen sections $(40 \mu)$ stained with cresyl violet. Data for statistical analysis were taken only from rats whose placements fell within the right lateral ventricle. Four rats were excluded from the analysis on the basis of cannula placement.

\section{RESULTS AND DISCUSSION}

The results from Experiment 2A are depicted in Fig. 2.

Baseline TFLs did not differ significantly among the groups. They ranged from $3.64 \pm 0.09 \mathrm{~s}$ in the $\mathrm{AF}+\mathrm{Sal}$ Group to $3.48 \pm 0.17 \mathrm{~s}$ in the BB + MS Group, $\mathrm{F}(3,20)<1.0$.

A 3-way ANOVA (Agonist $\times$ Enhancer $\times$ Time) revealed a significant Agonist $\times$ Enhancer interaction, $F(1,20)=29.09$, $p<0.0001$. The probe of the interaction for simple effects indicated that, as planned, our dose of centrally administered morphine in the absence of amniotic fluid ingestion produced a small $(10 \%)$ increase in TFL. This increase was not statistically significant, $F(1,20)=1.77, p>0.05$. In contrast, centrally administered morphine in conjunction with amniotic-fluid ingestion produced a significant elevation in TFL (analgesia) at both time measures, $\mathrm{F}(1,20)=73.07, p<0.0001$; $\mathrm{MS}+\mathrm{AF}$ treatment produced about a $92 \%$ elevation from baseline at $20 \mathrm{~min}$ and about a $98 \%$ elevation from baseline at $40 \mathrm{~min}$, whereas MS + BB treatment produced only about a $10 \%$ elevation in pain threshold. In rats receiving central saline injections, no change 
from baseline was observed regardless of the fluid ingested, $\mathrm{F}(1,20)<1.0$.

Experiment 2B: Central Morphine Administration and Blocked Peripheral Receptors

METHOD

\section{Subjects}

The subjects were 18 nulliparous, Long-Evans (hooded) rats, 90-150 days of age, with a mean body weight of $282 \pm 4.1 \mathrm{~g}$. The rats were morphine-naive, but had previously experienced a single TFL test. The subjects were housed and maintained identically to those in Experiment $2 \mathrm{~A}$.

\section{Apparatus}

Measurement of TFL, infusion of fluids, and intracerebroventricular administration of drugs were conducted as in Experiment $2 \mathrm{~A}$.

\section{Procedure}

Each rat was assigned to one of two Enhancer groups [AF, BB $(0.25 \mathrm{ml}, \mathrm{PO})]$. All rats received a central injection of morphine sulfate, MS $(2.5 \mu \mathrm{g}$ in $2.0 \mu \mathrm{l}$, ICV), and a systemic injection of QN $(8 \mathrm{mg} / \mathrm{kg}, \mathrm{SC})$. Pain threshold was measured 20 and 40 min after the orogastric infusion of AF or BB.

The sequence of treatments was identical to that used in Experiment $2 \mathrm{~A}$, except that a systemic injection of $\mathrm{QN}$ was given $20 \mathrm{~min}$ prior to determination of baseline TFL, to block peripheral but not central opioid receptors.

All surgical and histological procedures were the same as those in Experiment 2A. Four rats were excluded from the analysis because of inaccurate cannula placement.

\section{RESULTS AND DISCUSSION}

The results of Experiment $2 \mathrm{~B}$ are depicted in Fig. 3.

A 1-way ANOVA comparing TFL baselines showed that they did not differ between the AF and BB groups, $F(1,12)<1.0$.

Analysis by 2-way ANOVA did not yield statistically significant results. Inspection of the data revealed that the variability of responses at 40 min was greater than at $20 \mathrm{~min}$ (primarily due to the change in response of one rat). Since our main goal was to determine whether AF treatment enhanced analgesia at any time, the 20 -min time point was analyzed separately by 1-way ANOVA. This analysis revealed that at $20 \mathrm{~min}$ after infusion, AF ingestion did significantly elevate pain threshold in $\mathrm{QN}$-treated rats receiving ICV MS, $\mathrm{F}(1,12)=5.33, p<0.05$.

Since peripheral opioid receptors were blocked in this experiment, the results clearly show that amniotic-fluid ingestion, and therefore POEF ingestion, enhances the analgesic effect of centrally administered morphine by action on central opioid receptors. The combined results of Experiments 1 and 2 do not exclude the possibility of an effect of POEF on the peripheral action of morphine in addition to enhancement of the central action of morphine.

\section{EXPERIMENT 3}

The third experiment examined whether eliminating the central action of morphine also prevented enhancement of analgesia by ingestion of amniotic fluid. Enhancement of systemically administered morphine was measured while central opioid receptors were blocked by centrally administered QN.
METHOD

\section{Subjects}

The subjects were 18 nulliparous, female, Long-Evans (hooded) rats, 90-150 days of age, with a mean body weight of $284 \pm 5.9 \mathrm{~g}$. All rats had experienced a single TFL test in a prior study, but none had been exposed to morphine. The rats were housed and maintained in a manner identical to those in Experiment 2.

\section{Apparatus}

TFL assessment, fluid infusion, and intracerebroventricular drug administration were conducted as in Experiment 2.

\section{Procedure}

Each subject was assigned to one of two Enhancer groups [AF, BB $(0.25 \mathrm{ml}, \mathrm{PO})]$. The rats in both groups received a systemic injection of MS (3 mg/kg, IP) and a central injection of QN $(8.0 \mu \mathrm{g}$ in $2.0 \mu \mathrm{l}$, ICV). Analgesia was assessed $15 \mathrm{~min}$ after orogastric infusion of Enhancer.

The sequence of treatments was similar to that employed in Experiment 1, except that the QN was injected intracerebroventricularly to block the central action of morphine.

The procedures used in surgery for implantation of indwelling intracerebroventricular cannulae and verification of cannula placement were identical to those employed in Experiment 2. Histological examination of brain sections revealed that four cannula placements did not fall within the right lateral ventricle; those rats were therefore excluded from statistical analysis.

\section{RESULTS AND DISCUSSION}

The baseline TFLs did not differ significantly between the AF and $\mathrm{BB}$ Groups, $\mathrm{F}(1,12)<1.0$.

The 1-way ANOVA showed that AF ingestion did not elevate pain threshold in rats treated with systemic morphine and central QN. The mean \% change from baseline TFL for rats treated with $\mathrm{AF}$ was $-1.84 \pm 2.39 \mathrm{~s}$ and for rats treated with $\mathrm{BB}$ was $+1.27 \pm 1.50 \mathrm{~s}, \mathrm{~F}(1,12)=1.34, p>0.05$. Since centrally administered QN restricts morphine to its peripheral action, this result in combination with the results of Experiment 1 suggests that AF ingestion does not enhance the peripheral analgesic effects of morphine.

\section{GENERAL DISCUSSION}

The results of this study clearly show that ingestion of POEF in amniotic fluid enhances opiate-mediated analgesia by affecting the central action of morphine.

In Experiment 1, a blockade of peripheral opiate receptor sites attenuated, but did not eliminate, enhancement of systemic-morphine-mediated analgesia by amniotic-fluid ingestion. This result is consistent with an effect on a central opioid mechanism. In Experiment 2, AF ingestion enhanced the analgesic effect of central morphine administration both with and without blockade of peripheral opioid receptors. The combined results of Experiments 1 and 2 unequivocally demonstrate that ingestion of amniotic fluid, and therefore POEF, enhances the central locus of opiate action, but do not preclude the possibility that it also enhances the peripheral locus. The results of Experiment 3 suggest that a blockade of central opiate receptors prevents the enhancement of systemic-morphine-mediated analgesia by amniotic-fluid 
ingestion. In conjunction with the results of Experiments 1 and 2 , this result provides compelling evidence that ingestion of POEF in amniotic fluid enhances the central action of morphine exclusively.

\section{ACKNOWLEDGEMENTS}

We thank Dr. Herbert Merz and Boehringer Ingelheim for generously donating the quaternary naltrexone. This research was supported by NSF grant BNS 88-19837, awarded to M.B.K.

\section{REFERENCES}

1. Bianchi, G.; Fiocchi, R.; Tavani, A.; Manara, L. Quaternary narcotic antagonists' relative ability to prevent antinociception and gastrointestinal transit inhibition in morphine-treated rats as an index of peripheral selectivity. Life Sci. 30:1875-1883; 1982.

2. Brown, D. R.; Goldberg, L. I. The use of quaternary narcotic antagonists in opiate research. Neuropharmacology 24:181-191; 1985.

3. Doerr, J. C.; Kristal, M. B. Enhancement of opioid-mediated analgesia by ingestion of amniotic fluid: Onset latency and duration. Physiol. Behav. 46:913-915; 1989.

4. Kristal, M. B.; Abbott, P.; Thompson, A. C. Dose-dependent enhancement of morphine-induced analgesia by ingestion of amniotic fluid and placenta. Pharmacol. Biochem. Behav. 31:351-356; 1988.

5. Kristal, M. B.; Tarapacki, J. A.; Barton, D. Amniotic fluid ingestion enhances opioid-mediated but not nonopioid-mediated analgesia. Physiol. Behav. 47:79-81; 1990.

6. Kristal, M. B.; Thompson, A. C.; Abbott, P. Ingestion of amniotic fluid enhances opiate analgesia in rats. Physiol. Behav. 38:809-815; 1986.

7. Kristal, M. B.; Thompson, A. C.; Abbott, P.; Di Pirro, J. M.; Fer- guson, E. J.; Doerr, J. C. Amniotic-fluid ingestion by parturient rats enhances pregnancy-mediated analgesia. Life Sci. 46:693-698; 1990.

8. Kristal, M. B.; Thompson, A. C.; Grishkat, H. L. Placenta ingestion enhances opiate analgesia in rats. Physiol. Behav. 35:481-486; 1985.

9. Levine, J. D.; Taiwo, Y. O. Involvement of the mu-opiate receptor in peripheral analgesia. Neuroscience $32: 571-575 ; 1989$.

10. Pellegrino, L. J.; Pellegrino, A. S.; Cushman, A. J. A stereotaxic atlas of the rat brain. New York: Plenum Press; 1979.

11. Russell, J.; Bass, P.; Goldberg, L. I.; Schuster, C. R.; Merz, H. Antagonism of gut, but not central effects of morphine with quaternary narcotic antagonists. Eur. J. Pharmacol. 78:255-261; 1982.

12. Valentino, R. J.; Herling, S.; Woods, J. H.; Medzihradsky, F.; Merz, H. Quaternary naltrexone: Evidence for the central mediation of discriminative stimulus effects of narcotic agonists and antagonists. J. Pharmacol. Exp. Ther. 217:652-659; 1981.

13. Yaksh, T. L.; Al-Rodhan, N. R.; Jensen, T. S. Sites of action of opiates in production of analgesia. Prog. Brain Res. 77:371-394; 1988. 